\title{
Sonoro silêncio: um comentário sobre o aborto em Florianópolis, em dois tempos
}

Resenha do livro: Motta, Flávia de Mattos. Sonoro Silêncio: história e etnografia do aborto. Ponta Grossa: Todapalavra, 2015, 217p.

Natan Schmitz Kremer

Graduando em Ciências Sociais - UFSC Pesquisador vinculado ao NEPESC/UFSC natan_kremer@hotmail.com 
Lançado em 2015, o livro Sonoro silêncio: bistória e etnografia do aborto, da antropóloga e professora da Universidade do Estado de Santa Catarina (UDESC) Flávia de Mattos Motta, apresenta contribuições para pensarmos o aborto na cidade de Florianópolis em dois tempos.

Dividido em quatro capítulos, o primeiro, mais histórico, apresenta resultados de uma pesquisa desenvolvida ainda nos anos de 1990, com financiamento da Fundação Carlos Chagas, cujo objetivo era uma história social (que a autora chama de bistória etnográfica) do aborto na primeira metade do século XX, em Florianópolis - embora seja estabelecido algum diálogo com Porto Alegre. Os três próximos capítulos, que passaremos a considerar enquanto a segunda parte da obra, apresentam resultados do projeto Práticas Contraceptivas e Aborto em Grupos Populares Urbanos, refletindo, ainda, sobre a prática feminista de devolução dos dados, uma Antropologia Compartilhada, pensando na ética e no engajamento na pesquisa feminista.

$\mathrm{Na}$ primeira parte do livro (primeiro capítulo), a autora se dedica a estudar o aborto na primeira metade do século XX em Florianópolis, em diálogo com Porto Alegre. Mesclando fontes documentais e fontes orais, afirma: "encontrei mais que opacidade na minha procura por documentação a respeito das mulheres que praticaram aborto no século XX: encontrei um hiato, um enorme silêncio” (MOTTA, 2015, p. 27). Dentre os poucos documentos encontrados, Flávia trabalha com processos criminais e com histórico de internações de um importante hospital da capital catarinense, o Hospital de Caridades.

Entre os dilemas postos pela autora, podemos perceber o período de modernização que acomete a cidade nestas seis primeiras décadas do século XX, e o surgimento de práticas higienistas e de saneamento básico emergentes na cidade ${ }^{2}$. Aqui, a medicina popular realizada pelas mulheres da Ilha passa a ser estigmatizada frente às técnicas científicas de saúde, realizadas pelos homens. Influenciada por Foucault, mostra que existe um saber, que é poder, sobre as práticas médicas. Entretanto, e também com Foucault, percebe que este poder não é unilateral. A autora percebe que existe um polo de poder feminino, pensado na forma de manutenção dos nomes das filhas, em consonância com os nomes maternos - compreendendo estes nomes dentro de seu 
caráter simbólico.

Ao fazer um levantamento dos nomes das mulheres que encontra em sua pesquisa documental, organizará tabelas (p. 90-91) nas quais propõe um comparativo entre os nomes das mães e das filhas, percebendo algumas categorias de análise: nome da mãe acrescido de outro nome, ou manutenção de um dos nomes da mãe... Inspirada em Darnton, que nos diz que quando não entendemos uma piada estamos diante de algo maior que não entendemos, Motta (2015, p. 93) diz que, ao não entender um nome, também algo não encontramos. Assim, a autora afirma que sua hipótese "é que o sistema de nomeação revelado (...) [fale de] uma sociedade em que as mulheres populares assumiam uma centralidade em suas famílias. (...) Os nomes femininos que passam de mãe para filha nos falam de relações de gênero em que a mulher assume um poder peculiar", poder este que, para Sonia Maluf, está mais presente em uma esfera prática, material, do que em uma esfera discursiva (embora seja parte fundamental da vida nas comunidades interioranas de Florianópolis, influenciadas pela colonização açoriana):

Os modelos apresentados pelos moradores apontam para uma rígida divisão sexual das atividades, segundo a qual as mulheres são responsáveis pelas tarefas ligadas à casa e seus arredores e os homens por aquelas ligadas à roça e à pesca. Mas uma análise mais apurada faz aparecer uma distância entre esse modelo e as práticas efetivas de homens e mulheres. Nos longos períodos em que o homem está ausente da comunidade e da convivência familiar, envolvido no trabalho de pesca em Santos ou Rio Grande, são as mulheres que assumem todas as atividades de sustentação e reprodução familiar (MALUF, 1992, p. 99-100)

Voltando aos documentos do Hospital de Caridades, Flávia Motta percebe que:

Quanto à situação de classe das mulheres internadas por aborto, é difícil julgar pelos dados da documentação do Hospital de Caridade. A única pista diz respeito ao tipo de quarto que ocuparam: $1^{a}$ classe, $2^{a}$ classe, enfermarias ou sala reservada ( $3^{a}$ classe), sendo as duas últimas categorias para pacientes mais pobres. Das pacientes (...) a grande maioria esteve internada nessas duas últimas categorias. (...) Entre os 24 abortos infectados, apenas um mereceu internação na $1^{a}$ classe. (...) É instigante [,entretanto,] a constatação de que, em sua maioria, as curetagens dos primeiros (...) dizem respeito a internações de $1^{a}$ classe" (MOTTA, 2015, p. 52-53)

O fragmento acima exposto é bastante evidente: existe, provavelmente, um apagamento dos relatos históricos sobre aborto das camadas mais altas de Florianópolis 
- pois, como mostra Flávia, é esta mesma elite que escreve a história da cidade, através de seus documentos.

Ainda analisando os documentos deste hospital, a autora trará uma argumentação interessante ao pensar na idade das mulheres que realizavam aborto em Florianópolis neste período: eram, geralmente, mulheres mais velhas e com muitos filhos e que, em grande parte dos casos, voltavam a ter filhos após a realização de um aborto. Assim, aponta a prática do aborto como uma forma contraceptiva, "como forma de espaçamento entre gerações" (MOTTA, 2015, p. 29), se opondo aos discursos popularizados e infundados de que o aborto seria realizado por jovens descuidadas.

A autora ainda pensará na construção de um sentimento de infância e amor materno, chegando a outra reflexão que parece relevante em sua argumentação - em especial, e sobre a qual voltará nos próximos capítulos do livro, a de que "a gravidez só é gravidez quando é socialmente e subjetivamente percebida e construída enquanto tal: quando é assumida" (MOTTA, 2015, p. 85).

O que chamamos de segunda parte, os três capítulos subsequentes, trazem reflexões sobre o aborto em Florianópolis nos dias atuais. O segundo capítulo (p. 125172) traz uma etnografia de um bairro popular de Florianópolis; no terceiro (p. 173-200), apontamentos acerca das representações do aborto no espiritismo; e, por fim, no capítulo 4 (p. 201-217), a autora reflete sobre o processo de devolução dos dados da pesquisa, articulando com reflexões sobre ética e política na pesquisa feminista.

No segundo capítulo, Não conta pra ninguém: o aborto segundo mulheres de uma comunidade popular em Florianópolis, a autora discutirá, a partir de trabalho de campo realizado em um bairro da capital catarinense, sobre "experiências, estratégias discursivas e conhecimentos (...) acerca do aborto" (MOTTA, 2015, p. 125). Percebemos aqui certo retorno da autora ao que havia ponderado anteriormente, embora neste momento seja recapitulado com uma reflexão mais densa sobre o tema.

Um dos temas que podemos encontrar neste capítulo trata dos discursos produzidos sobre o aborto e na referência às vizinhas. Escreve, refletindo: "quando falam da vizinha, essas mulheres estão antes fazendo um discurso sobre si mesmas. Elas constroem, aos olhos da entrevistadora, uma figura moral para si mesmas ao 
construírem os discursos sobre as outras ou diretamente sobre o aborto" (MOTTA, 2015, p. 141).

Pensando nesta figura moral, a autora perceberá uma distinção posta entre matar e fazer vir (que podemos relacionar ao sentimento de infância discutido na primeira parte do livro), onde jogos de moralidades estão postos em cena. Como já exposto acima, aponta para a dificuldade de se chegar a narrações sobre abortos e práticas abortivas, sendo estas, quando narradas, destinadas às experiências das vižinhas. Entretanto, ao questionar sobre o funcionamento de um dos chás abortivos, uma das informantes comenta, intuitivamente, algo como isso jamais funcionou comigo. Assim, Flávia aponta para a existência de jogos de moralidades que envolvem a questão do aborto, e as diferenças entre matar (que só pode dar após a criação de um sentimento de infância), geralmente realizado pelas outras, as vizinhas; e do fazer vir, escondido, rápido, logo após o atraso da primeira menstruação.

Como apresenta no capítulo seguinte, Vida interrompida: o espiritismo nas representações sociais do aborto, existem muitos fenômenos que influenciam a prática do aborto, dentre eles o religioso. Segundo uma de suas informantes, "a religião católica só diz que não, [mas] a espírita explica tudo” (MARIA apud MOTTA, 2015, p. 173). Estas explicações criam, também, todo um agravante moral. Conversando com informantes espíritas que praticaram o aborto, a autora perceberá que estas geralmente apontam para o arrependimento da prática e a promessa de não fazê-lo outra vez. Opondo-se a este comportamento, uma de suas informantes, também espírita, diz que não se arrepende do que fez e que abortaria novamente. Para compensar o erro, faz trabalho comunitário em um centro espírita. Ao ser consultada, entretanto, sobre o aborto por anencefalia, se posiciona contrariamente, afirmando que, se existe o desejo de ter um filho, não deve ser negado por má-formação genética. Assim, parece interessante pensarmos nos diversos jogos morais postos em cena.

Como exposto acima, os escritos de Flávia trazem contribuições para pensar as práticas de aborto na cidade de Florianópolis em uma perspectiva histórica e a partir de etnografias atuais, entrecruzadas com diversos problemas da contemporaneidade, como a problemática de classe e religiosidades, a partir do campo dos Estudos de Gênero e da 
Antropologia Feminista.

No último capítulo, por fim, pensará no processo de devolução dos dados à comunidade pesquisada e no engajamento da pesquisa feminista. Após o trabalho de campo e o processo de análise dos dados coletados, as coordenadoras do projeto de pesquisa a partir do qual os dois últimos capítulos foram gerados prepararam um calendário e uma cartilha ilustrada, com a explicação de utilização de diversos métodos contraceptivos, entregues após uma tarde de diálogo com as interlocutoras - criando uma relação de reciprocidade, confiança e ensinamento, o que, como apontam Anahí Mello, Felipe Fernandes e Miriam Grossi (2013, p. 11), marca a construção do campo da teoria feminista no Brasil, pois “o campo da teoria feminista e dos estudos de gênero é, desde sua emergência, um campo híbrido de produção de conhecimentos que produz práticas e que é por sua vez informado e transformado por essas práticas".

É possível pensar, entretanto, como aponta Miriam Grossi (2011), que este campo dos Estudos de Gênero, ainda na década de 1970/1980, constitui-se tendo como problema central a problemática das violências afetivo-conjugais, percebendo assim certo silêncio frente às lutas pelo direito ao corpo das mulheres. Assim, pois, embora publicado apenas em 2015, pode-se perceber como a primeira parte do livro Sonoro silêncio: história e etnografia do aborto trata-se de uma pesquisa pioneira, realizada ainda em meados da década 1990.

Dotada deste pioneirismo, destacamos como, ao longo de suas páginas, dois pontos nos parecem os de maior relevância em seu texto: o primeiro, estratégias metodológicas para ouvir o silêncio que engloba a temática, seja em uma perspectiva histórica, a partir das perguntas que realiza aos documentos com os quais trabalha, seja em uma perspectiva etnográfica, na realização do trabalho de campo e nas pistas que dá sobre o estabelecimento da confiança na relação com suas interlocutoras; o segundo ponto, a relevância do cuidado com as questões éticas da pesquisa, a partir de uma Antropologia Compartilhada, no processo de devolução dos dados às suas interlocutoras, criando estratégias para a manutenção das relações ou, se preferirmos, da dádiva.

\section{Notas}

1. Agradeço às avaliadoras anônimas pela leitura atenta ao texto. 
2. Para pensar os processos de modernização de Nossa Senhora do Desterro/Florianópolis, recomenda-se os trabalhos de Araujo (1989) e Moraes (1999).

\section{Referências bibliográficas}

ARAUJO, Hermetes de. A Invenção do Litoral: reformas urbanas e reajustamento social em Florianópolis na primeira república. Dissertação: Mestrado em História. Pontifica Universidade Católica de São Paulo, 1989.

GROSSI, Miriam. Violência, gênero e sofrimento. In RIFIOTIS, Theophilos; RODRIGUES, Tiago. Educação em Direitos Humanos: discursos críticos e temas contemporâneos. $2^{\mathrm{a}}$ Ed, Florianópolis: EDUFSC, 2011.

MALUF, Sônia. Bruxas e Bruxaria na Lagoa da Conceição: um estudo sobre representações de poder feminino na Ilha de Santa Catarina. Revista Crítica de Ciências Sociais, nº $^{\circ}$ 4, 1992.

MELLO, Anahí Guedes de; FERNANDES, Felipe Bruno Martins; GROSSI, Miriam. Entre pesquisas e militar: engajamento político e construção da teoria feminista no Brasil. Revista Artemis, $\mathrm{n}^{\circ}$ 15, 2013.

MORAES, Laura do Nascimento. Cães, vento sul e urubus: higienização e cura em Desterro/Florianópolis (1830-1918). Tese: Doutorado em História. Pontifícia Universidade Católica do Rio Grande do Sul, 1999.

MOTTA, Flávia de Mattos. Sonoro Silêncio: história e etnografia do aborto. Ponta Grossa: Todapalavra, 2015. 